\title{
O terapeuta é um cientista?
}

\section{Is the therapist a scientist?}

\section{¿El terapeuta es un científico?}

\author{
Sérgio Vasconcelos de Luna ${ }^{1}$
}

[1] PUCSP - Pontifícia Universidade Católica de São Paulo I Título abreviado: O terapeuta é um cientista? I Endereço para correspondência: I Email: svluna@ pucsp.br I DOI: 10-18761/PAC.TAC.2019.015 | Nota: Republicação autorizada pelo autor de artigo originalmente publicado em Luna, S. V. (1997). O terapeuta é um cientista?. In: Banaco, R. A.. (Org.). Sobre Comportamento e Cognição: aspectos teóricos, metodológicos e de formação em análise do comportamento e terapia cognitiva. Santo André: ARBytes Editorial. (pp. 305-313).

Resumo: Após sucessivas dificuldades de encaminhar respostas à pergunta original - O terapeuta é um cientista? -, considerou-se que o estrangulamento estava na maneira como a pergunta estava formulada após o que se procurou responder à seguinte questão: é possível que o profissional produza sistematicamente conhecimento novo (portanto, relevante para a comunidade científica) enquanto age como terapeuta? Note-se que não se questionou se seria possível que um terapeuta fosse também um pesquisador (assumido ponto de partida). A questão que se apresentou, então, foi: a atividade profissional do terapeuta pode atender aos requisitos para caracterizar a pesquisa, tomados como sendo a) a existência de um pergunta ou conjunto e perguntas cuja resposta é importante encontrar porque configura conhecimento novo e relevante teórica e/ou socialmente; b ) a elaboração de um conjunto de passos que permitam obter informação necessária para chegar à resposta; c) um sistema de referência que permita tratar e analisar as informações obtidas; d) a indicação do grau de confiabilidade na(s) resposta(s) encontrada(s) (em outras palavras, por que aquela(s) resposta(s), nas condições da pesquisa, é(são) a(s) melhor(es) resposta(s) possível(eis)?). A partir de então, analisou-se e se contrapôs a atividade de terapeuta e do pesquisador, enfatizando-se os seguintes aspectos: 1. compromisso epistemológico e tipo de ênfase na formação; 2 . desenvolvimento metodológico; 3 . timing da pesquisa e da intervenção clínica. $\mathrm{O}$ resultado desse exercício permaneceu ambíguo. Nos termos das análises feitas e apresentadas, as conclusões levam a dizer que as contingências são todas desfavoráveis e, portanto, a junção das duas atividades é pouco provável de ser mantida sistematicamente. Mas, há outro conjunto de elementos que precisam ser considerados e que foram empurrando, ao longo das reflexões, para outro caminho de análise: a) $\mathrm{O}$ que deve reunir profissionais e pesquisadores não é uma curva acumulada, uma linguagem, nem um conjunto de procedimentos, mas uma maneira de encarar as relações recíprocas entre comportamento e meio. b) Há imensas lacunas no conhecimento de que se dispõe sobre essas relações e provavelmente muitas maneiras diferentes de produzi-lo. Se houver concentração na demonstração da funcionalidade do conhecimento produzido, provavelmente serão reduzidos os ruídos que se estabelecem sobre as melhores maneiras de produzi-lo. c) Essa concentração na funcionalidade do conhecimento dependerá do esforço conjunto daqueles que se dedicam à produção do conhecimento, à prestação de serviços e sobretudo daqueles que conseguem produzir conhecimento enquanto intervêm na situação natural. d) Valerá a pena tentar esse esforço coletivo; porém, será ainda mais proveitoso se se conseguir eliminar os vícios de formação, especialmente aqueles que transformam a competência teórico-metodológica e a produção de conhecimento em opção, em vez de fazer dela um compromisso epistemológico com a Psicologia e ético com o cliente e com o homem.

Palavras-chave: terapeuta e pesquisador; terapeuta e cientista; pesquisa em intervenção; análise do comportamento. 
Abstract: Summary. Several unsuccessful attempts were made to respond the original question: is therapist a scientist? In this process, it seemed clear that the bottleneck was in the manner it was formulated. Given such an assumption, the original question was so rephrased: is it conceivable that a professional come to systematically produce (new) knowledge (therefore relevant to scientific community) while working as a therapist? It should be noted that it was not questioned the possibility that a therapist be also a researcher (what was taken for granted). The questions then posed was: therapist's professional activity can meet the criteria established to characterize scientific research, assumed as: a) a question or a set of questions whose answers are important to find because they will provide us with new knowledge, theoretically and /or socially relevant; b) a set of planned steps taken in order to gather necessary information so as to reach questions raised by the research problem; c) a theoretical framework presiding the treatment and interpretation of gathered information; $d$ ) the demonstration of the degree in which the final response(s) is(are) reliable, that is, demonstration of the reasons why obtained answers, given the research context, are the best answers to be offered. From then on, an exercise was made in order to analyse and confront the activity of both the researcher and therapist, from the standpoint of: 1 . the epistemological commitment and mais focus, during university years, in intervention and/or research; 2. methodological developments in behavior analysis; 3. the timing along research and clinical intervention. The product of such an exercise showed that possible answers to the main question remained unclear, ambíguos. Given analysis realized, conclusions reached point that contingencies under which therapists work are all quite unfavorable, meaning that it seems very unlikely that joint action (research and intervention) can be exerted in systematic ways. However, other elements must be considered and they kept pushing, along analysis, to another path. a) What should bond together therapists and researchers isn't a learning curves, a jargon, not even a set of procedures, but a way of thinking and describing reciprocal relations between individual and environment. b) There exist huge gaps in available knowledge about those relations and, most certainly, several different ways of filling in those gaps. c) Focusing in the function of knowledge about behavior will depend on joint efforts of those whose main objective is to produce knowledge via research, of those who dedicates their work to intervention and, especially of those who are successful in producing knowledge while intervening in natural environments. d) Such a collective effort will be worthwhile, but it will even more worthwhile if able to overcome certain tendencies like taking methodological competence and knowledge production as professional's option, rather than assuming these competences as epistemological commitment with psychology and ethical principles towards the client and men.

Keywords: Therapist and researcher; therapist and scientist; research and intervention; behavior analysis 
Resumen: Después de sucesivas dificultades de encaminar respuestas a la pregunta original - ¿El terapeuta es un científico? -, se consideró que el estrangulamiento estaba en la manera como la pregunta estaba formulada, después de lo que se buscó responder a la siguiente cuestión: ¿es posible que el profesional produzca sistemáticamente conocimiento nuevo (por lo tanto, relevante para la comunidad científica) mientras actúa como terapeuta? Se nota que no se cuestionó si sería posible que un terapeuta fuera también un investigador (asumido punto de partida). La cuestión que se presentó, entonces, fue: la actividad profesional del terapeuta puede atender a los requisitos para caracterizar la investigación, tomados como a) la existencia de una pregunta o conjunto y preguntas cuya respuesta es importante encontrar porque configura conocimiento nuevo y relevante teórico y / o socialmente; b) la elaboración de un conjunto de pasos que permitan obtener la información necesaria para llegar a la respuesta; c) un sistema de referencia que permita tratar y analizar la información obtenida; d) la indicación del grado de confiabilidad en la (s) respuesta (s) encontrada (s) (en otras palabras, por qué esa (s) respuesta (s), en las condiciones de la investigación, es (s) la (s) mejor (s) (es) respuesta (s) posible (s)?). A partir de entonces, se analizó y se contrapuso la actividad de terapeuta y del investigador, enfatizando los siguientes aspectos: 1. compromiso epistemológico y tipo de énfasis en la formación; 2. desarrollo metodológico; 3. tiempo de la investigación y de la intervención clínica. El resultado de ese ejercicio permaneció ambiguo. En términos de los análisis hechos y presentados, las conclusiones llevan a decir que las contingencias son todas desfavorables y, por lo tanto, la unión de las dos actividades es poco probable que se mantenga sistemáticamente. Pero, hay otro conjunto de elementos que necesitan ser considerados y que fueron empujando a lo largo de las reflexiones a otro camino de análisis: a) Lo que debe reunir profesionales e investigadores no es una curva acumulada, un lenguaje, ni un conjunto de procedimientos, sino una manera de encarar las relaciones recíprocas entre comportamiento y medio. b) Hay muchas lagunas en el conocimiento de que se dispone sobre esas relaciones y probablemente muchas maneras diferentes de producirlo. Si hay concentración en la demostración de la funcionalidad del conocimiento producido, probablemente se reducirán los ruidos que se establecen sobre las mejores maneras de producirlo. c) Esa concentración en la funcionalidad del conocimiento dependerá del esfuerzo conjunto de aquellos que se dedican a la producción del conocimiento, a la prestación de servicios y sobre todo de aquellos que logran producir conocimiento mientras intervienen en la situación natural. d) valdrá la pena intentar este esfuerzo colectivo; sin embargo, será aún más provechoso si se logra eliminar los vicios de formación, especialmente aquellos que transforman la competencia teórico-metodológica y la producción de conocimiento en opción, en vez de hacer de ella un compromiso epistemológico con la Psicología y ético con el cliente y con el hombre.

Palabras-clave: terapeuta e investigador; terapeuta y científico; investigación en intervención; análisis del comportamiento. 
Meu artigo pressupõe uma declaração necessária: não sou, não fui um terapeuta nem tive formação para sê-lo. Qualquer competência que me autorize a tratar deste tema vem do lado da pesquisa. Por outro lado, considerando-se que este fato é conhecido, imagino que a ideia dos proponentes da atividade de que participei e que gerou este trabalho foi mesmo a de ter alguém falando como pesquisador, e não como terapeuta.

As primeiras considerações que me ocorreram sobre o tema não foram muito claras e eu atribuí as ambiguidades ao título. Mesmo trocando a palavra cientista por pesquisador (o que ajudou), eu não resolvia o problema. Não imaginava que fosse possível perguntar se todo terapeuta era um pesquisador e, muito menos, se algum poderia sê-lo. Afinal, muitos terapeutas têm produzido e divulgado conhecimento de qualidade, e este encontro - assim como os anteriores - é prova disso. Nesta linha de raciocínio, concluí que a questão importante a responder era esta: em que condições um profissional pode ser sistematicamente - pesquisador e terapeuta ao mesmo tempo? Em outras palavras, é possível que ele produza sistematicamente conhecimento durante ou mediante sua atividade como terapeuta?

Essa pergunta está circunscrita dentro de um problema com o qual tenho me ocupado (Cf. Luna, 1989; Luna, 1992; Luna, 1996/2009 ${ }^{1}$ ): trata-se da distinção entre o pesquisar e o prestar serviços, e eu gostaria de gastar algum tempo tratando dela.

Independentemente do referencial teórico-metodológico do profissional, uma pesquisa teórica, empírica ou de qualquer outra natureza pressupõe necessariamente, a meu ver, quatro requisitos:

a) a existência de uma pergunta cuja resposta é importante encontrar porque configura conhecimento novo;

b) a elaboração (e sua descrição) de um conjunto de passos que permitam obter informação necessária para chegar à resposta;

c) um sistema de referência que permita tratar e analisar as informações obtidas;

d) a indicação do grau de confiabilidade na resposta encontrada (em outras palavras, por que

1 A primeira data refere-se ao ano da primeira publicação. A segunda, da última reimpressão. aquela resposta, nas condições da pesquisa, é a melhor resposta possível?).

Esses elementos permitem caracterizar mais claramente a distinção entre o pesquisar e o prestar serviços. Os critérios de relevância que presidem à formulação de um problema de pesquisa levam a esperar que a resposta a ser obtida ao final da pesquisa - constatada a correção metodológica - seja relevante para a comunidade científica, por preencher uma lacuna importante no conhecimento disponível. Desse modo, pesquisa é sempre um elo entre o pesquisador e a comunidade científica, razão pela qual a sua publicidade é elemento indispensável ao processo de produção de conhecimento. Conhecimento não divulgado não é conhecimento, e seu produtor não é pesquisador.

Nos projetos de prestação de serviços, o profissional (não necessariamente o pesquisador) defronta-se com um interlocutor (indivíduo, grupo, comunidade) que apresenta um problema que, para maior facilidade de comunicação, identificarei aqui como "queixa". Cabe ao profissional identificá-la (ou levar o seu cliente a fazê-lo) e colocar sua competência a serviço do encaminhamento de soluções. Dessa forma, um projeto de intervenção parte da "queixa" e tem como ponto de chegada a sua solução. Se isso ocorrer, ter-se-á configurado uma bem-sucedida prestação de serviços.

A aparente obviedade dessas considerações começa a ser abalada quando se consideram projetos de intervenção que se pretendem pesquisas e/ou que são relatados como tais. Nessas circunstâncias, tenho observado a ocorrência de certas configurações que merecem consideração, duas das quais comento:

Configuração 1: O projeto é relevante pelos seus efeitos (isto é, profissional e cliente consideram-se satisfeitos com os resultados), mas não há indicação de seus procedimentos nem avaliação dos resultados; em outras palavras, torna-se difícil até caracterizar a ação profissional, seja de pesquisa, seja de intervenção.

Configuração 2: $\mathrm{O}$ relato da pesquisa dá conta da queixa e da sua solução; contudo, nem queixa nem solução são relevantes para a comunidade científica, na medida em que não constituem conhecimento novo para ela. Embora pais 
fiquem aliviados por saberem que a enfermidade de seu filho foi identificada e curada, dificilmente seu médico dele iria a um congresso para comunicar seu procedimento para identificar sarampo e tratar dele.

Em resumo, independentemente da relevância de que cada uma dessas atividades se revista, pesquisa e prestação de serviços não se confundem, nem mesmo quando ambas são desenvolvidas conjuntamente. Por mais verdadeiro que seja o fato de que teoria e prática precisam interagir continuamente e por mais indiscutível que seja a necessidade do compromisso do pesquisador com a transformação da realidade, permanece o fato de que ambas - pesquisa e prestação de serviços - têm interlocutores diferentes e desempenham funções diferentes no processo de desenvolvimento do conhecimento.

Essas declarações deveriam ser suficientes para estabelecer minha posição quanto ao valor indiscutível de cada uma dessas atividades e sobretudo da importância fundamental da troca contínua entre os respectivos profissionais. Mas, a pergunta que me fizeram é outra e pode ser reformulada agora: é possível que o terapeuta produza sistematicamente conhecimento novo (portanto, relevante para a comunidade científica) enquanto intervém na situação profissional? Note-se que não se questiona se é possível que um terapeuta seja também um pesquisador. Comecei este texto afirmando essa possibilidade.

A questão que apresento é se sua atividade profissional, na qualidade de terapeuta, pode atender aos requisitos vigentes para caracterizar a pesquisa.

Acredito que possíveis respostas a essa questão advenham da análise de prováveis contingências, a controlar atividades do pesquisador e do terapeuta.

Mencionei, há pouco, requisitos mínimos que permitem caracterizar uma pesquisa. Embutido nesses requisitos, existe um sistema de referência e de controle, nem sempre explicitado, mas inexorável. Por exemplo, quem decide, referenda a importância da resposta que se procura buscar? Seria ingênuo pressupor que baste o julgamento do próprio pesquisador. Da mesma forma, de onde vêm os critérios que o pesquisador deve satisfazer para afirmar (e ter credibilidade ao fazê-lo) que a resposta encontrada é a melhor resposta possível?
A resposta a essas e a muitas outras perguntas semelhantes aponta um sistema de avaliação/referendo exercido, em muitos níveis diferentes, pela comunidade de pares do pesquisador. Esse sistema começa com a disseminação genérica dos referenciais teórico-metodológicos aceitáveis para a produção de conhecimento em um determinado tempo (a história da ciência mostra quanto eles são sujeitos a mutação) e desce a níveis menos sutis representados por pareceres a trabalhos submetidos a financiamento ou a publicação e pela avaliação realizada a teses e dissertações na pós-graduação (trajetória meio inevitável ao postulante a pesquisador).

Em síntese, o pesquisar desenvolve-se segundo normas gerais estabelecidas e controladas pelo próprio grupo de pesquisadores. Como em qualquer outra confraria, a adesão a essas normas é condição para o estabelecimento do status de cada um em particular e de todos em geral. Para que esse processo ocorra, é preciso que os produtos da atividade de pesquisa tenham um caráter necessariamente público.

Por outro lado, como estabelecer esses correlatos em relação ao terapeuta? Que contingências existem no sentido de levá-lo a tornar público o seu produto? Sob que condições pode ocorrer a avaliação de seus pares? Garantida a habilitação mínima e salvaguardado o código de ética, que tipo de controle pode ser exercido sobre a sua atividade? Como é estabelecido o status profissional de um terapeuta não pesquisador?

Acredito que existem diferenças marcantes entre as contingências controladoras desses dois grupos de profissionais que eu reúno em três grupos, descritos e analisados a seguir:

1. compromisso epistemológico e ênfase no tipo de formação;

2. desenvolvimento metodológico;

3. timing da pesquisa e da intervenção clínica.

\section{Compromisso epistemológico e ênfase no tipo de formação:}

É muito difícil avaliar o que controla um profissional em sua atividade de pesquisa. Embora curiosidade e compromisso com o conhecimento sejam motivações elegantes e tentadoras, a verdade é que antes precisamos descartar uma série de outros candidatos sérios a controladores (tais como a 
necessidade de titulação, exigências contratuais e a própria manutenção de status). Além disso, como qualquer outro tipo de controle, esses precisam ser instalados ao longo da história de vida. Há consenso quanto ao fato de que essa instalação precisaria ser iniciada cedo, mas a literatura sobre Ensino de Ciências (tanto a europeia quanto a norte-americana) é farta em críticas ao insucesso da iniciação de crianças no jogo da ciência. Em nível nacional, não faltam críticas dos próprios órgãos responsáveis pelo ensino à fragilidade da formação em pesquisa que se desenvolve ou que nem se tenta desenvolver nos cursos de formação.

A despeito disso, a comparação entre as formações de futuros terapeutas e de futuros pesquisadores, no que diz respeito ao compromisso com a produção de conhecimento, fala muito alto a favor dos segundos. Não tenho dados a esse respeito, mas todos os meus indicadores sugerem que a preocupação com a capacitação do profissional para a intervenção clínica aliada à multiplicidade de abordagens, cada qual reclamando a necessidade de alta especialização e ocorrendo em um tempo exíguo, tem levado os alunos a interpretar a formação em pesquisa, ou pelo menos a competência teórico-metodológica, como mais uma opção profissional, assim como eles optam, por exemplo, entre clínica e trabalho. Uma das imagens mais claras de que guardo dos meus tempos de professor de metodologia no curso de graduação é a de alunos justificando seu desinteresse pela disciplina, por já terem feito a opção pela clínica. Uma aluna chegou a declarar que deveria ser dispensada da disciplina porque não pretendia ser cientista! Em conversas com amigos terapeutas, durante a preparação deste texto, recebi de um deles um curioso alerta: o de que supervisores clínicos (de alunos e de recém-formados) e associações congregando terapeutas estavam desenvolvendo um tal nível de supervalorização da intervenção e controle sobre ela, que não sobraria espaço para cogitar sobre a produção de conhecimento na atuação clínica!

Um último ponto precisa ser assinalado dentro deste tópico. As discussões que se vêm travando, nos últimos anos, sobre a dissociabilidade ensino-pesquisa e, em especial, sobre o caráter profissionalizante do ensino de graduação tendem a reforçar uma separação entre aqueles que produzem conhe- cimento e aqueles que vão consumi-lo (inteligentemente, esperamos todos) na atividade profissional. Dentro das universidades, principalmente as particulares, não é estranho que se defendam contratos muito reduzidos a determinados professores e que eles fiquem isentos de uma produção compatível com a função da universidade, sob a alegação de que sua experiência profissional é indispensável à formação do aluno. A alegação é perfeita. O que não se justifica é que a sua experiência profissional venha carrear ao aluno o modelo de uma intervenção que não se compromete com a geração de conhecimento novo e sua exposição à crítica.

Se, de fato, essas análises estiverem corretas, a formação do terapeuta criará poucas contingências - se alguma - na direção de um compromisso com a produção de conhecimento. Nessas circunstâncias, sobraria aquilo que Gile e Carrascosa (1985) e Hewson (1985) chamaram, respectivamente, de compromissos metodológicos e de compromissos epistemológicos, para manter um profissional pesquisando. Mas, afinal, o que teria instalado, em primeiro lugar, tais compromissos?

\section{Desenvolvimento metodológico}

Anos atrás, em um simpósio na Reunião Anual da atual Sociedade Brasileira de Psicologia, tive oportunidade de analisar a situação da pesquisa aplicada em relação à pesquisa básica, dentro da Análise Experimental do Comportamento, e concluí que a primeira enfrentava tremendas dificuldades em virtude dos modelos metodológicos impostos pela segunda. Embora não seja o caso de retomar aquela análise agora, vale ressaltar alguns pontos nela assinalados.

A natureza dos princípios epistemológicos da AEC, a ênfase na Psicologia como ciência natural, os seus pressupostos metodológicos e o longo período de "caça às bruxas" que se abateu sobre os seus adeptos, por exemplo, geraram uma expectativa segundo a qual a pesquisa que não atendesse aos padrões estabelecidos para o e/ou pelo trabalho básico de laboratório seria uma pesquisa de categoria inferior, ou nem seria pesquisa. Eu diria que, nos últimos anos, muito mudou nesse cenário, mas tenho a impressão de que as mudanças não chegaram a desfazer os efeitos inicialmente produzidos sobre os que desenvolvem atividades ditas aplicadas. 
De fato, se, no caso particular da clínica psicológica, tiverem de ser mantidos critérios da pesquisa experimental, tais como as análises que permitem identificar operantes, os critérios de estabilidade e os procedimentos para a identificação da mudança comportamental, então a clínica acabará se reduzindo a um laboratório em que o problema de pesquisa assume primazia sobre a "queixa" do cliente. Em outras palavras, devemos abrir mão da possibilidade de que a AEC venha a permitir a pesquisa durante a intervenção clínica.

Não acredito que seja esse o caso, mas suspeito de que seja essa a interpretação vigente. Tenho um antigo projeto, nunca concretizado, de procurar entender por que alguns brilhantes e críticos analistas do comportamento abandonaram a AEC, justamente no momento em que abandonaram a área acadêmica ou assumiram atividades profissionais fora dela. Porque brilhantes, eles poderão ter se convencido da insuficiência da abordagem para além dos limites da pesquisa; mas porque críticos, poderão ter abandonado a AEC por sucumbirem ao peso das exigências metodológicas em uma situação adversa exigindo intervenção precoce.

Um dos piores vícios da AEC, a meu ver, foi o que sempre chamei "fetichização" do procedimento, ou seja, situações (e há vários exemplos delas) em que o comportamento é escolhido para estudar o procedimento, e não vice-versa, o que só se justifica como pesquisa metodológica. Aliás, temo que isso já esteja ocorrendo em relação às relações de equivalência.

Além desse fetiche - ou por causa dele -, a AEC mostrou-se extraordinariamente lenta em desenvolver tecnologias alternativas que - sem prejuízo dos pressupostos epistemológicos e dos critérios metodológicos - atendessem às peculiaridades dos vários fenômenos em que comportamentos estão envolvidos. Com isso, acabamos circunscrevendo a natureza e o tipo de fenômenos que podemos estudar, fazendo com que a crítica do behaviorismo radical ao behaviorismo metodológico servisse também a ele. Há muito tempo, Kantor (1970) fez em vão essa crítica à AEC.

Desse ponto de vista, não chega a ser surpreendente se os profissionais voltados para a prestação de serviços não produzirem, de fato, conhecimento, embora caiba também e principalmente a eles a criatividade metodológica. No entanto, a situação de intervenção clínica é um dos maiores celeiros de um fenômeno que os pesquisadores, de alguns para cá, passaram a privilegiar: o relato verbal. Mais do que isso, as pesquisas produzidas sobre o assunto, a despeito dos cuidados tomados, frequentemente pecam por um aspecto sobre o qual o terapeuta tem quase total controle: o contexto. Dificilmente um pesquisador terá tanta oportunidade de discriminação e de generalização dos controles que se exercem sobre o comportamento verbal de um indivíduo quanto aquela que é facultada a um terapeuta. $\mathrm{E}$ aos que hesitarem quanto à validade metodológica, para a AEC, de uma pesquisa não experimental sobre relatos verbais, basta lembrar que o Verbal Behavior (Skinner, 1957) é um belo exemplo de tradução, de interpretação não experimental dos princípios estabelecidos experimentalmente pela AEC.

Em conclusão, as características teórico-epistemológicas da AEC, firmadas com base na pesquisa experimental de laboratório, não favorecem o trabalho daqueles que dedicam à prestação de serviços, e eu diria em particular aos terapeutas. Simultaneamente, nem sempre está claro o quanto essas características são parte integrante de um modelo teórico-epistemológico de produção de conhecimento e o quanto representam apenas necessidades da pesquisa básica em relação aos problemas propostos para estudo.

Essas circunstâncias podem ajudar a explicar por que, durante muito tempo, profissionais que se dedicavam à prestação de serviços evitaram a divulgação de seus trabalhos em encontros mais gerais: esta poderia ter sido a forma encontrada de evitar a "aversividade" das críticas admitidamente pesadas. Embora alguns trabalhos merecessem mesmo a crítica, outros poderiam ser discriminados por ousarem destoar do modelo metodológico imposto pela pesquisa básica.

Por outro lado, pesa também sobre esses prestadores de serviços a morosidade ou a inércia no desenvolvimento de tecnologia eficiente e adequada aos fenômenos sobre os quais trabalham.

\section{Timing da pesquisa e da intervenção clínica}

Este tópico representa um desdobramento do anterior, mas com peculiaridade suficiente para 
ser analisado à parte. Grande parte do fetiche do procedimento a que me referi há pouco, e quase com certeza da morosidade no desenvolvimento de tecnologia "procedural", advém de uma deformação no nosso procedimento de ensino em geral e da AEC em particular: trata-se da tendência a transmitir fatos, regras, procedimentos, em vez de ensinar o indivíduo a pensar; no nosso caso, a pensar em termos de contingências. Tal aprendizado é fundamental para que a AEC constitua verdadeiramente uma maneira eficiente de lidar com o comportamento onde quer que ele ocorra e nas circunstâncias em que ocorrer.

Para começar, o pesquisador tem quase todos os graus de liberdade para escolher o seu problema de pesquisa, o âmbito em que pretende estudá-lo, estabelecer os critérios para a seleção de sujeitos e escolher entre as alternativas metodológicas possíveis, o que acaba se refletindo no atendimento às regras metodológicas da comunidade quando da divulgação/publicação dos resultados. A decisão do terapeuta quando ao que "pode"/"deve"/ ser divulgado e quanto ao que atende ou não às normas vigentes para divulgação/publicação do material pode depender da discriminação, dentre os casos clínicos que considera bem sucedidos, daqueles com menor possibilidade de ruído metodológico.

Em segundo lugar, e talvez mais crucial para o problema em questão, está o papel desempenhado pelo cliente em relação àquele desempenhado pelo sujeito de pesquisa. Com exceção do caso de um terapeuta diretivo, em uma terapia diretiva, o timing do processo terapêutico pode estar muito mais na dependência do cliente do que do terapeuta. Por outro lado, em condições gerais, o timing de uma pesquisa fica mais sob o controle do pesquisador do que do sujeito, até porque este pode vir a ser substituído.

Nessas condições, resta ao terapeuta que pretenda produzir conhecimento, enquanto intervém na situação clínica, o desenvolvimento de um raciocínio metodológico ágil e criativo que permita simultaneamente manter-se sob o controle das necessidades do cliente e daquelas da comunidade que julgará a sua produção. Do ponto de vista epistemológico, o que interessa à comunidade é o conhecimento novo produzido, não o bem-estar do cliente; obviamente, do ponto de vista do cliente, a direção é inversa.

\section{Refazendo um caminho}

Em vez da pergunta inicial - O terapeuta é um cientista? -, e do que posso ter lido a respeito do assunto, acredito que tenha pesado em minha tarefa o exercício de tentar concretamente interpretar possíveis contingências, de um lado e de outro, dos dois polos de atividades.

O resultado desse exercício é, para mim, ambíguo. Nos termos das análises que fiz e apresentei aqui, minhas conclusões levam-me a dizer que as contingências são todas desfavoráveis e, portanto, a junção das duas atividades é pouco provável de ser mantida sistematicamente. Mas, há outro conjunto de elementos que precisam ser considerados e que foram me empurrando, ao longo de minhas reflexões, para outro caminho de análise.

Em nenhum momento, ocorreu-me ser necessário explicitar o que eu chamava de pesquisa ou produção de conhecimento. Mas, tudo leva a crer que este seja um elemento chave dentro dessa questão. Se, por esse termo, entendermos a pesquisa experimental, valerão as análises feitas até aqui. Por outro lado, de há muito se vem insistindo em uma distinção importante entre o que seria a Análise Experimental do Comportamento e a Análise do Comportamento. Também, há muito tempo, os etólogos simpatizantes do Behaviorismo Radical de Skinner (e.g. Warren \& Warren, 1977) ) vêm apontando quanto a AEC teria a ganhar se usasse o seu arsenal conceitual para entender as relações que se estabelecem foram das condições artificiais do laboratório. Além disso, conforme já apontado aqui, poucos pesquisadores disporão, em momento algum, das condições privilegiadas dos terapeutas no que diz respeito ao uso, importância e significado dos relatos verbais.

É perfeitamente concebível para mim o desenvolvimento de um tipo de pesquisa por terapeutas em que fenômenos simulados pelo laboratório sejam colocados à prova na situação clínica e a generalidade ampla de alguns princípios seja reduzida em favor de uma compreensão maior de fatores com possibilidade de interferir nos fenômenos contemplados.

Provavelmente isso não será possível com todos os casos clínicos com que se defronta um terapeuta, mas o compromisso com a produção de conheci- 
mento poderá vir a desenvolver o que chamei de criatividade metodológica e tornar essa possibilidade cada vez mais concreta.

A minha ambiguidade ante a pergunta a que me referi há pouco decorre do fato de dar-me conta de que ela vem sendo formulada, há muito tempo, dentro de um contexto que não é o da situação clínica; consequentemente, as respostas estarão demarcadas pelos mesmos parâmetros que circunscreveram a pergunta. Entretanto, acredito que a situação possa ser alterada. Se vocês me permitem a pretensão, gostaria de concluir com sugestões nesse sentido.

a) O que nos deve reunir não é uma curva acumulada, uma linguagem, nem um conjunto de procedimentos, mas uma maneira de encarar as relações recíprocas entre comportamento e meio.

b) Há imensas lacunas no conhecimento de que dispomos sobre essas relações e provavelmente muitas maneiras diferentes de produzi-lo. Se nos concentrarmos na demonstração da funcionalidade do conhecimento produzido, provavelmente reduziremos os ruídos que se estabelecem sobre as melhores maneiras de produzi-lo.

c) Essa concentração na funcionalidade do nosso conhecimento dependerá do esforço conjunto daqueles que se dedicam à produção do conhecimento, à prestação de serviços e sobretudo daqueles que conseguem produzir conhecimento enquanto intervêm na situação natural.

d) Valerá a pena tentar esse esforço coletivo; porém, será ainda mais proveitoso se conseguirmos eliminar os vícios de formação, especialmente aqueles que transformam a competência teórico-metodológica e a produção de conhecimento em opção, em vez de fazer dela um compromisso epistemológico com a Psicologia e ético com o cliente e com o homem.

\section{Bibliografia}

Gil, D. \& Carrascosa, J. (1985) Science learning as conceptual and methodological change. European Journal of Science Education, 7 (3), 231-236. doi:10.1080/0140528850070302

Hewson, P. W. (1985) Epistemological commitments in the learning of science. European
Journal of Science Education, 7 (2), 163-172. doi: 10.1080/0140528850070207

Kantor, J. R. (1970) An analysis of The Experimental Analysis of Behavior (TEAB). Journal of Experimental Analysis of Behavior, 13, 101-108. doi: 10.1901/jeab.1970.13-101

Luna, S. V. de (1989) O falso conflito entre tendências metodológicas. ln: I. Fazenda (Org.), Metodologia da Pesquisa Educacional. São Paulo: Cortez.

Luna, S. V. de (1992) Prestar serviços e pesquisar: algumas distinções necessárias. Universidade e Educação. Coletânea CBE. São Paulo: Papirus.

Luna, S. V. de (2009) Planejamento de Pesquisa. Uma Introdução - Coleção Trilhas (Português) Publicação original de 1996

Skinner, B. F. (1957) Verbal Behavior. New Jersey: Prentice-Hall.

Warren, A. R. \& Warren, S. F. (1977) Ecological Perspectives in Behavior Analysis. Baltimore: University Park Press.

\section{Informações do Artigo}

Histórico do artigo:

Versão definitiva recebida em: 29/04/2019

Editor Associado: Denis Roberto Zamignani 